\title{
A Factory-Scale Application of Secondary Adjunct Cultures Selected from Lactic Acid Bacteria During Puzzone di Moena Cheese Ripening
}

\author{
E. Franciosi, ${ }^{*}$ L. Settanni, ${ }^{, 1}$ S. Carlin, $\dagger$ A. Cavazza, ${ }^{*}$ and E. Poznanski ${ }^{*}$ \\ ${ }^{*}$ Edmund Mach Foundation, Istituto Agraria di San Michele all'Adige (IASMA) Research Centre, Agri-Food Quality Department, \\ Food Microbiology and Technology Research Unit, Via E. Mach 1, 38010 San Michele a/A (TN), Italy \\ †Edmund Mach Foundation, IASMA Research Centre, Agri-Food Quality Department, Quality and Nutrition Research Unit, Via E. Mach 1, \\ 38010 San Michele a/A (TN), Italy
}

\begin{abstract}
The lactic acid populations of 2 seasonal Puzzone di Moena cheeses made from winter and summer raw cow's milk were characterized at different ripening times. Lactic acid bacteria (LAB) were isolated on selective media and subjected to genetic typing and identification. The species most frequently found during ripening were Lactobacillus paracasei ssp. paracasei, Lactobacillus plantarum, and Pediococcus pentosaceus. The different strains recognized by random amplification of polymorphic DNA-PCR were characterized for their acidifying and proteolytic activities to select nonstarter LAB to be used as secondary adjunct cultures (SAC). For each of the 3 above species, a strain showing weak acidification and high proteolytic capacity was selected. The 3 strains (Lb. paracasei ssp. paracasei P397, Lb. plantarum P399, and P. pentosaceus $\mathrm{P} 41$ ) constituted a mixed SAC used at 2 levels of concentration $\left(10^{3}\right.$ and $10^{4} \mathrm{cfu} / \mathrm{mL}$ ) in experimental cheese making at dairy factory-scale. The analysis of volatile organic compounds as well as sensory analyses showed that the preferred level of SAC inoculation was $10^{3} \mathrm{cfu} / \mathrm{mL}$.
\end{abstract}

Key words: nonstarter lactic acid bacteria, Puzzone di Moena cheese, raw cow's milk, secondary adjunct culture

\section{INTRODUCTION}

The microorganisms involved in cheese making and ripening may have 2 different origins. Basically, they can be present as indigenous microbiota from raw materials, environment, or equipment, or all three, or, otherwise, carefully selected cultures may be added to the bulk raw or heat-treated milk. The latter group of microorganisms includes the primary starters represented by some lactic acid bacteria (LAB) whose main

Received October 9, 2007.

Accepted April 19, 2008.

${ }^{1}$ Corresponding author: luca.settanni@iasma.it role is to ensure consistent acid development during cheese making. The secondary cultures, which includes nonstarter LAB (NSLAB), staphylococci, micrococci, coryneforms, propionibacteria, yeasts, and molds, provide well-defined functions, such as gas production, surface coloration, softening, and, through their diverse enzymatic systems, development of characteristic aromas (Parente and Cogan, 2004).

Nonstarter LAB are generally present in raw milk, and they increase from a low number in fresh curd to dominate the microbiota of mature cheese (Peterson and Marshall, 1990). In contrast to primary starters, NSLAB well tolerate the hostile environment of cheese during ripening, which is typically characterized by low moisture, high salt concentration, low $\mathrm{pH}$, and a deficiency of nutrients (Fryer and Sharpe, 1966; Turner et al., 1986). Mesophilic lactobacilli predominate the NSLAB community, but pediococci, leuconostocs, and enterococci are also generally found (Fitzsimons et al., 1999; Beresford and Williams, 2004). Lactobacillus casei ssp. casei, Lb. casei ssp. pseudoplantarum, Lactobacillus paracasei ssp. paracasei, and Lactobacillus plantarum are the species most frequently isolated from cheese, but other facultatively and obligately heterofermentative Lactobacillus species are also detected (Jordan and Cogan, 1993; Gobbetti et al., 1999). Adventitious mesophilic lactobacilli may be present in pasteurized milk, because some of them may survive heat treatments or as result of a posttreatment contamination, or both (Turner et al., 1986).

Raw milk cheeses are typical products whose quality is strongly influenced by the local production area and by its traditions (Micari et al., 2007). Most of the Italian cheeses with registered denomination of origin are made from raw milk whose microbiota enhances the flavor of final products and, therefore, have received special attention (Morea et al., 1998; De Angelis et al., 2001; Randazzo et al., 2002). In these cases, cheese quality also depends on the characteristics of a given geographic area (Poznanski et al., 2004); this is the reason why raw materials and transformation process 
must be produced and performed, respectively, in defined areas as indicated in the cheese production regulations.

The presence of adventitious NSLAB introduces variability into the ripening process that cannot be easily controlled by the cheese maker. The species and strain composition of the nonstarter Lactobacillus population may exhibit not only interfactory differences (Antonson et al., 2001; De Angelis et al., 2001) but also differences in cheeses produced at the same factory of different days and in cheeses from different vats on the same day (Fitzsimons et al., 1999; Williams et al., 2002). Puzzone di Moena is a regional Trentino smear cheese made from raw cow's milk. Due to the different microbial populations (concentration and species and strain composition) hosted in milk, such a production may be subjected to fluctuations in the final characteristics, in particular, greater differences have been revealed between summer and winter cheeses (practical observations). Thus, the development of secondary adjunct cultures (SAC), able to ensure the dominance of wanted strains, is crucial to minimize microbial variability during the ripening process.

This work is part of a project aimed to select LAB and NSLAB strains to be used as primary starters and secondary cultures, respectively, in traditional regional Trentino cheese productions. In particular, the objectives of the present study were (1) to characterize LAB evolution during ripening of Puzzone di Moena cheese, (2) to select NSLAB strains to be used as secondary cultures, and (3) to evaluate their persistence and effect on the overall characteristics in experimental cheese making.

\section{MATERIALS AND METHODS}

\section{Cheese Production and Isolation of LAB}

The traditional cheese process of Puzzone di Moena is schematically represented in Figure 1. This product, also known as Spretz Tzaorì in the local dialect, is typical of the Moena area that is located in the north part of Italy, in the alpine province of Trento. To characterize LAB species evolution during Puzzone di Moena production, cheese making was investigated during 2 seasonal (summer and winter) productions; samples of cheese after $24 \mathrm{~h}, 10 \mathrm{~d}$, and 1, 2, and $3 \mathrm{mo}$ of ripening were used for isolation (Table 1).

Cheese samples (25 g) were homogenized (2 min at high speed) by means of a stomacher (Laboratory Blender Stomacher 400, Seward, London, UK) and serially diluted in peptone $\mathrm{H}_{2} \mathrm{O}$ [0.1\% mycological peptone (Oxoid, Basingstoke, UK)]. Decimal dilutions were plated onto the following media for microbial counts: kanamycin aesculin azide (Oxoid) agar, aerobically in- cubated at $37^{\circ} \mathrm{C}$ for $24 \mathrm{~h}$ for enterococci; de Man-RogosaSharpe (MRS; Oxoid) agar acidified at pH 5.5 with 5 $M$ acetic acid for rods; and M17 (Oxoid) agar for cocci, incubated at 30 and $45^{\circ} \mathrm{C}$ for $48 \mathrm{~h}$, for recovery of mesophilic and thermophilic LAB, respectively. Except M17 at $30^{\circ} \mathrm{C}$, plates were anaerobically incubated, and, after growth, colonies of various shapes (at least 5 with identical morphology) were randomly picked from count plates and transferred to the corresponding broth media; enterococci were inoculated into M17 broth medium. The isolates were purified by successive subculturing. The purity of the cultures and cell morphology were checked microscopically. Gram-positive [Gregersen $\mathrm{KOH}$ method (Gregersen, 1978)] and catalasenegative (determined by transferring fresh colonies from a petri dish to a glass slide and adding $5 \% \mathrm{H}_{2} \mathrm{O}_{2}$ ) isolates were stored in glycerol at $-80^{\circ} \mathrm{C}$ until further experimentations.

\section{Genomic DNA Extraction and Typing of LAB}

Cell lysis for DNA extraction was performed by the Instagene Matrix kit (Bio-Rad, Hercules, CA) as described by the manufacturer. Crude cell extracts were used as template for PCR reactions.

Strain differentiation was performed by random amplification of polymorphic DNA-PCR (RAPD-PCR) analysis in a $25-\mu \mathrm{L}$ reaction mix using primer PC1 (Poznanski et al., 2004), AB111, and AB106 (van den Braak et al., 2000). Amplifications were performed by means of PTC-100 Thermal Cycler (MJ Research Inc., Waltham, MA). The PCR products were separated by electrophoresis on 1.5\% (wt/vol) agarose gel (Gibco BRL, Cergy Pontoise, France) and visualized by UV transillumination after staining with ethidium bromide $(0.5 \mu \mathrm{g} /$ $\mathrm{mL}$ ). Deoxyribonucleic acid ladder $1 \mathrm{~Kb}$ (Invitrogen, Carlsbad, CA) was used as a molecular size marker. The RAPD-PCR profiles were analyzed with the pattern analysis software package Gel Compar Version 4.1 (Applied Maths, Kortrijk, Belgium). Calculation of similarities of band profiles was based on Pearson product moment correlation coefficient. Dendrograms were obtained by means of the unweighted pair group method using arithmetic average clustering algorithm.

\section{Identification of $L A B$}

Genotypic identification of LAB with different RAPDPCR profiles was carried out by a genetic polyphasic approach consisting of PCR-denaturing gradient gel electrophoresis (DGGE) of the V3 region of the 16S rRNA gene, partial 16S rRNA gene sequencing, and species-specific and multiplex PCR.

Deoxyribonucleic acids of isolates with different RAPD-PCR profiles were first analyzed by PCR-DGGE. 
A

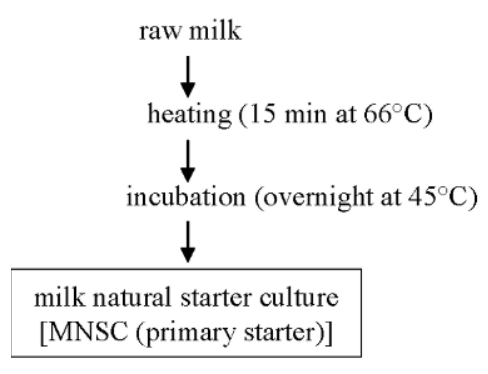

B

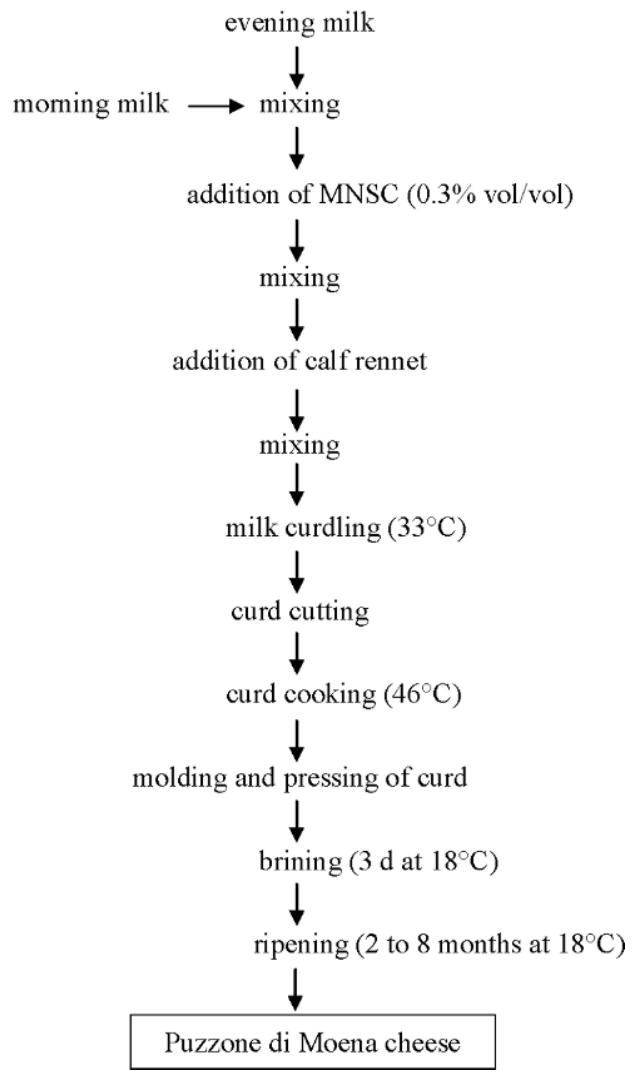

Figure 1. General flow diagram of traditional Puzzone di Moena cheese production: (A) production of primary starter culture for inoculum; (B) cheese-making process.

The DGGE samples were prepared by performing PCR amplification of the V3 region of the 16S rRNA gene according to Ercolini et al. (2001). Size and quantities of PCR products were determined in $2 \%$ agarose gel. The DGGE was carried out using the DCcode Universal Mutation Detection System (Bio-Rad) on $16 \mathrm{~cm} \times 16$ $\mathrm{cm} \times 1 \mathrm{~mm}$ gels. The PCR products $(8 \mu \mathrm{L})$ were loaded on gels with $8 \%(\mathrm{wt} / \mathrm{vol}$ ) acrylamide (acrylamide-bisacrylamide $37.5: 1$ ) and a 25 to $60 \%$ of urea and formamide gradient, increasing in the direction of electrophoresis. A $100 \%$ denaturing solution consisted of $7 M$ urea and 40\% (vol/vol) deionized formamide. Electrophoresis was conducted in $1 \times$ TAE [40 mM Tris, 20 $\mathrm{m} M$ acetic acid, and $1 M$ EDTA (pH 8.0)] buffer at 150 $\mathrm{V}$ for $5 \mathrm{~h}$ at $60^{\circ} \mathrm{C}$. After runs, gels were stained for 15 min in an ethidium bromide solution, rinsed in distilled $\mathrm{H}_{2} \mathrm{O}$ for 20 min, and photographed on a UV transilluminator table. Reference strains (type strains or strains identified in previous works) were included in DGGE analysis for species comparison.

Strains that remained unspeciated were then subjected to the 16S rRNA gene sequence analysis using the Lab159f/Uni515r primer pair as described by Heilig et al. (2002). The PCR product (ca. $30 \mathrm{ng}$ ) of each strain was purified with Exo-SAP-IT kit (USB Co., Cleveland, $\mathrm{OH}$ ) and sequenced through the BigDye Terminator v1.1 cycle sequencing kit (Applied Biosystems, Foster City, CA) as reported by the manufacturer in a ABI PRISM 3100 sequencer (Applied Biosystems). Sequences were compared with the Ribosomal Database Project II sequences (Maidak et al., 2001) for species assignment. In the case of sequences with percentage of identity lower than 100\%, but at least $97 \%$ (Stackebrandt and Goebel, 1994), species were assigned by means of species-specific and multiplex PCR. Species belonging to the Lb. casei-Lb. paracasei-Lactobacillus rhamnosus 16S rRNA gene group were processed with the primers Y1, Y2, Casei, Para, and Rham in speciesspecific PCR assays as described by Ward and Timmins (1999). Differentiation between Lactococcus lactis ssp. lactis and Lc. lactis ssp. cremoris was performed by a PCR assay with primers LcLfor and LcLrev (Corroler et al., 1998). Multiplex PCR assays were necessary to better identify enterococci and pediococci: the $\operatorname{sod} A$ 
Table 1. Lactic acid bacteria (LAB) counts and species during traditional Puzzone di Moena cheese ripening

\begin{tabular}{|c|c|c|c|c|c|c|c|c|c|c|}
\hline \multirow[b]{2}{*}{ Samples ${ }^{1}$} & \multicolumn{5}{|c|}{ LAB counts ${ }^{2}(\log \mathrm{cfu} / \mathrm{g})$} & \multicolumn{5}{|c|}{ Species identified $^{3}$} \\
\hline & $\begin{array}{l}\text { MRS } \\
\left(30^{\circ} \mathrm{C}\right)\end{array}$ & $\begin{array}{l}\text { MRS } \\
\left(45^{\circ} \mathrm{C}\right)\end{array}$ & $\begin{array}{l}\text { M17 } \\
\left(30^{\circ} \mathrm{C}\right)\end{array}$ & $\begin{array}{l}\text { M17 } \\
\left(45^{\circ} \mathrm{C}\right)\end{array}$ & KAA & $\begin{array}{l}\text { MRS } \\
\left(30^{\circ} \mathrm{C}\right)\end{array}$ & $\begin{array}{l}\text { MRS } \\
\left(45^{\circ} \mathrm{C}\right)\end{array}$ & $\begin{array}{l}\text { M17 } \\
\left(30^{\circ} \mathrm{C}\right)\end{array}$ & $\begin{array}{l}\text { M17 } \\
\left(45^{\circ} \mathrm{C}\right)\end{array}$ & KAA \\
\hline WC1 & $\begin{array}{l}6.0 \pm \\
0.3\end{array}$ & $\begin{array}{l}5.9 \pm \\
0.2\end{array}$ & $\begin{array}{l}6.7 \pm \\
0.1\end{array}$ & $\begin{array}{l}8.9 \pm \\
0.2\end{array}$ & $\begin{array}{l}6.0 \pm \\
0.2\end{array}$ & Enterococcus faecalis & E. faecalis & $\begin{array}{l}\text { (E. faecalis), } \\
\text { Lactococcus lactis } \\
\text { ssp. cremoris }\end{array}$ & $\begin{array}{l}\text { Streptococcus } \\
\text { thermophilus }\end{array}$ & E. faecalis \\
\hline $\mathrm{WC} 2$ & $\begin{array}{l}9.0 \pm \\
0.2\end{array}$ & $\begin{array}{l}6.8 \pm \\
0.3\end{array}$ & $\begin{array}{l}8.6 \pm \\
0.3\end{array}$ & $\begin{array}{l}8.7 \pm \\
0.3\end{array}$ & $\begin{array}{l}5.1 \pm \\
0.4\end{array}$ & $\begin{array}{l}\text { Lactobacillus } \\
\text { paracasei } \\
\text { ssp. paracasei, } \\
\text { (Pediococcus pentosaceus) }\end{array}$ & P. pentosaceus & $\begin{array}{l}\text { Lc. lactis ssp. } \\
\text { cremoris, } \\
(P . \text { pentosaceus })\end{array}$ & S. thermophilus & E. faecalis \\
\hline WC3 & $\begin{array}{l}7.9 \pm \\
0.2\end{array}$ & $\begin{array}{l}6.4 \pm \\
0.3\end{array}$ & $\begin{array}{l}7.5 \pm \\
0.1\end{array}$ & $\begin{array}{l}8.3 \pm \\
0.3\end{array}$ & $\begin{array}{l}5.2 \pm \\
0.2\end{array}$ & $\begin{array}{l}\text { Lb. paracasei } \\
\text { ssp. paracasei, } \\
\text { Lactobacillus rhamnosus, } \\
(P . \text { pentosaceus })\end{array}$ & P. pentosaceus & $\begin{array}{l}\text { Lc. lactis ssp. } \\
\text { cremoris, } \\
(P . \text { pentosaceus })\end{array}$ & S. thermophilus & E. faecalis \\
\hline WC4 & $\begin{array}{l}7.8 \pm \\
0.2\end{array}$ & $\begin{array}{l}7.3 \pm \\
0.1\end{array}$ & $\begin{array}{l}7.7 \pm \\
0.4\end{array}$ & $\begin{array}{l}8.0 \pm \\
0.1\end{array}$ & $\begin{array}{l}5.3 \pm \\
0.2\end{array}$ & $\begin{array}{l}\text { Lb. paracasei ssp. paracasei, } \\
(P . \text { pentosaceus })\end{array}$ & P. pentosaceus & P. pentosaceus & S. thermophilus & E. faecalis \\
\hline WC5 & $\begin{array}{l}7.7 \pm \\
0.2\end{array}$ & $\begin{array}{l}7.1 \pm \\
0.1\end{array}$ & $\begin{array}{l}7.5 \pm \\
0.2\end{array}$ & $\begin{array}{l}6.1 \pm \\
0.1\end{array}$ & $\begin{array}{l}5.2 \pm \\
0.2\end{array}$ & $\begin{array}{l}\text { Lb. paracasei ssp. paracasei, } \\
(P . \text { pentosaceus })\end{array}$ & P. pentosaceus & P. pentosaceus & S. thermophilus & E. faecalis \\
\hline SC1 & $\begin{array}{l}6.1 \pm \\
0.2\end{array}$ & $\begin{array}{l}5.6 \pm \\
0.3\end{array}$ & $\begin{array}{l}6.5 \pm \\
0.1\end{array}$ & $\begin{array}{l}8.9 \pm \\
0.2\end{array}$ & $\begin{array}{l}5.7 \pm \\
0.1\end{array}$ & $\begin{array}{l}\text { (E. faecalis), Lactobacillus } \\
\text { plantarum }\end{array}$ & E. faecalis & E. faecalis & S. thermophilus & E. faecalis \\
\hline SC2 & $\begin{array}{l}8.5 \pm \\
0.3\end{array}$ & $\begin{array}{l}7.0 \pm \\
0.1\end{array}$ & $\begin{array}{l}7.8 \pm \\
0.2\end{array}$ & $\begin{array}{l}7.6 \pm \\
0.3\end{array}$ & $\begin{array}{l}6.0 \pm \\
0.1\end{array}$ & $\begin{array}{l}\text { Lb. plantarum, Lb. paracasei } \\
\text { ssp. paracasei }\end{array}$ & P. pentosaceus & P. pentosaceus & S. thermophilus & E. faecalis \\
\hline $\mathrm{SC} 3$ & $\begin{array}{l}8.7 \pm \\
0.4\end{array}$ & $\begin{array}{l}7.8 \pm \\
0.4\end{array}$ & $\begin{array}{l}7.9 \pm \\
0.1\end{array}$ & $\begin{array}{l}7.8 \pm \\
0.1\end{array}$ & $\begin{array}{l}5.8 \pm \\
0.3\end{array}$ & $\begin{array}{l}\text { Lb. paracasei } \mathrm{ssp} \text {. paracasei, } \\
\text { Lb. plantarum, }(P . \text { pentosaceus })\end{array}$ & P. pentosaceus & $\begin{array}{l}\text { Lb. plantarum, } \\
(P . \text { pentosaceus })\end{array}$ & S. thermophilus & E. faecalis \\
\hline SC4 & $\begin{array}{l}8.9 \pm \\
0.3\end{array}$ & $\begin{array}{l}7.9 \pm \\
0.2\end{array}$ & $\begin{array}{l}7.9 \pm \\
0.1\end{array}$ & $\begin{array}{l}7.6 \pm \\
0.3\end{array}$ & $\begin{array}{l}5.7 \pm \\
0.3\end{array}$ & $\begin{array}{l}\text { Lb. paracasei } \mathrm{ssp} \text {. paracasei, } \\
\text { Lb. plantarum, (P. pentosaceus) }\end{array}$ & P. pentosaceus & $P$. pentosaceus & S. thermophilus & E. faecalis \\
\hline SC5 & $\begin{array}{l}7.1 \pm \\
0.2\end{array}$ & $\begin{array}{l}6.8 \pm \\
0.2\end{array}$ & $\begin{array}{l}7.7 \pm \\
0.3\end{array}$ & $\begin{array}{l}6.3 \pm \\
0.1\end{array}$ & $\begin{array}{l}5.5 \pm \\
0.3\end{array}$ & Lb. plantarum, $(P$. pentosaceus $)$ & P. pentosaceus & P. pentosaceus & S. thermophilus & E. faecalis \\
\hline
\end{tabular}

${ }^{1} \mathrm{WC} 1=$ winter cheese at $24 \mathrm{~h} ; \mathrm{WC} 2=$ winter cheese at $10 \mathrm{~d} ; \mathrm{WC} 3=$ winter cheese at $1 \mathrm{mo}$; WC4 = winter cheese at 2 mo; WC5 = winter cheese at 3 mo; SC1 = summer cheese at $24 \mathrm{~h} ; \mathrm{SC} 2=$ summer cheese at $10 \mathrm{~d}$; SC3 = summer cheese at $1 \mathrm{mo}$; SC4 = summer cheese at 2 mo; SC5 = summer cheese at 3 mo.

${ }^{2}$ Results indicate mean $\pm \mathrm{SD}$ of 2 independent counts.

${ }^{3}$ Species in brackets were counted at a subdominant concentration. 
gene-based strategy developed by Jackson et al. (2004) with primers DU1, DU2, FL1, FL2, FM1, FM2, MA1, and MA2 specific for Enterococcus durans, Enterococcus faecalis, Enterococcus faecium, and Enterococcus malodoratus and the multiplex PCR targeting the 16S rRNA and $l d h D$ genes with primers $\mathrm{Pac}, \mathrm{Ppe}, \mathrm{Pu}$, $l d h D F$, and $l d h D R$ specific for Pediococcus acidilactici and Pediococcus pentosaceus as reported by Mora et al. (1997). Species allotted into the Lb. plantarum ( $L b$. plantarum-Lactobacillus paraplantarum-Lactobacillus pentosus) group were analyzed by the recA genebased multiplex PCR reported by Torriani et al. (2001).

\section{Physiological Characterization}

Cells of LAB strains were washed twice in peptone $\mathrm{H}_{2} \mathrm{O}$ and inoculated (1\% vol/vol) in UHT milk for $48 \mathrm{~h}$ to evaluate the acidification kinetics. Proteolysis was estimated by the reaction of $o$-phthalaldehyde and 2mercaptoethanol with amino groups released during proteolysis of a protein substrate following the method of Church et al. (1985).

\section{Experimental Cheese Making}

Three strains representative of the most numerous RAPD-PCR clusters of NSLAB that showed a low acidifying capacity and a high proteolytic activity were chosen to be used as SAC. Lactobacillus paracasei ssp. paracasei $\mathrm{P} 397, L b$. plantarum $\mathrm{P} 399$, and $P$. pentosaceus $\mathrm{P} 41$ were cultured separately in MRS at $30^{\circ} \mathrm{C}$ for $24 \mathrm{~h}$. Cells were harvested by centrifugation at 6,500 $\times g$ for 10 min, washed twice with sterile peptone $\mathrm{H}_{2} \mathrm{O}$, and then resuspended; the cell suspension, diluted 1:10, gave an optical density $600 \mathrm{~nm}$ of ca. 1.25, which roughly corresponds to a concentration of $10^{9} \mathrm{cfu} / \mathrm{mL}$. Optical densities were measured by means of a biophotometer (Eppendorf AG, Hamburg, Germany).

Cheese trials were carried out at the dairy factory located in the Moena area (Caseificio Sociale di Predazzo e Moena, Predazzo, Trento, Italy) where traditional Puzzone di Moena samples were collected. Bulk raw cow's milk was maintained under stirring in a 8,000-L polyvalent vat and analyzed for indigenous LAB presence as reported previously for cheese. Three vats with a capacity of $1,000 \mathrm{~L}$ each were filled in with milk for cheese manufacturing. At the same time of natural (primary) starter culture addition, SAC were inoculated at a final concentration of about $10^{3}$ [experimental cheese A (ECA)] and $10^{4}$ [experimental cheese B (ECB)] cfu/mL in raw milk. A control cheese $(\mathbf{C C})$, without SAC addition, was also produced. Cheese trials were carried out in duplicate in 2 consecutive days (1 and 2).

\section{Persistence of Selected NSLAB}

The NSLAB populations in CC, ECA, and ECB were characterized after 3 mo of ripening. Microbiological counts and strain isolation were carried out as previously reported. After colony and cell inspection, species and strain recognition were performed by DGGE and RAPD-PCR analysis, respectively, as described previously.

\section{Sensory Analysis}

Six individuals highly experienced in the sensory analysis of Puzzone di Moena cheeses evaluated cheese samples considering specific sensory descriptors (egg, ammonium, stall, and butyric) previously defined to be characteristic of regional Trentino smear cheeses (Puzzone di Moena, Nostrano di Campitello, and Nostrano di Primiero; Endrizzi et al., 2005).

\section{Analysis of Cheese Volatile Organic Compounds}

Volatile compounds of ECA, ECB, and CC, after 3 mo of ripening, were determined using the headspace solid-phase microextraction method coupled with gas chromatography with mass spectrometric detection. Cheese samples were kept at $-20^{\circ} \mathrm{C}$ until analysis. Before analysis, each sample $(10 \mathrm{~g})$ was grated, transferred into a 40-mL vial, added with $1 \mathrm{~mL}$ of $\mathrm{H}_{2} \mathrm{O}$ and 50 $\mu \mathrm{L}$ of internal standard solution [4-methyl-2-pentanone $(4.02 \mathrm{~g} / \mathrm{L})$ and isobutyric acid $(20 \mathrm{~g} / \mathrm{L})$ in $\mathrm{H}_{2} \mathrm{O}$ ], and heated, under magnetic stirring, at $60^{\circ} \mathrm{C}$ until melting (ca. $25 \mathrm{~min}$; Carlin and Versini, 2005). Volatile fractions were adsorbed on DBV-Carboxen-PDMS fibers (Supelco, Bellefonte, PA) for $30 \mathrm{~min}$, and desorption was carried out at $250^{\circ} \mathrm{C}$ on a PerkinElmer AutoSystem XL gas chromatography coupled with a TurboMass Gold (PerkinElmer, Norwalk, CT) mass spectrometer. Separation was achieved on a HP-Innowax fused-silica capillary column $(30 \mathrm{~m}, 0.32 \mathrm{~mm}$ i.d., $0.5-\mu \mathrm{m}$ film thickness; Agilent Technologies). Transfer line temperature was $220^{\circ} \mathrm{C}$. The mass spectrometer operated in electron ionization mode (internal ionization source; $70 \mathrm{eV}$ ) with a scan range from $m / z 30$ to 300 . The results were expressed in milligrams per kilogram as 4-methyl-2-pentanone.

\section{RESULTS}

\section{Isolation, Identification, and Evolution of LAB}

Results of LAB enumeration and species identification from winter and summer Puzzone di Moena cheese samples are reported in Table 1. A selective growth of Streptococcus thermophilus and E. faecalis was ob- 
tained onto M17 incubated at $45^{\circ} \mathrm{C}$ and kanamycin aesculin azide, respectively. Pediococcus pentosaceus-specific counts were possible with MRS incubated at $45^{\circ} \mathrm{C}$, whereas $L b$. paracasei ssp. paracasei, Lb. rhamnosus, and $L b$. plantarum were all counted onto MRS incubated at $30^{\circ} \mathrm{C}$.

Twenty-four hours after production, both cheeses were characterized by the presence of almost the same species at similar concentrations: about $10^{6} \mathrm{cfu} / \mathrm{g}$ of $E$. faecalis and $10^{9} \mathrm{cfu} / \mathrm{g}$ of $S$. thermophilus. In addition to those species, in summer cheese, it was also detected the presence of $L b$. plantarum at $6.1 \mathrm{log} \mathrm{cfu} / \mathrm{g}$ and in winter cheese ca. $10^{6} \mathrm{cfu} / \mathrm{g}$ of Lc. lactis ssp. cremoris. During ripening, $S$. thermophilus was counted at decreasing levels till 6.1 to $6.3 \mathrm{log} \mathrm{cfu} / \mathrm{g}$ for winter and summer cheese, respectively, whereas $E$. faecalis was always counted from the $10^{-5}$ plate count (details on enterococci are being published elsewhere, Franciosi et al., 2008). Lactococcus lactis ssp. cremoris was found in winter cheese until 1 mo of ripening. From the 10th day onwards, $P$. pentosaceus was present in both cheeses in the ranges 6.8 (WC2) to $7.1 \mathrm{log} \mathrm{cfu} / \mathrm{g}$ (WC5) and 7.0 (SC2) to $6.8 \mathrm{log} \mathrm{cfu} / \mathrm{g}$ (SC5). From a total of ca. 460 colonies collected from various plates of MRS at $30^{\circ} \mathrm{C}$, it was estimated that, at each sampling time, $P$. pentosaceus was found at about 1 order of magnitude lower than $L b$. paracasei ssp. paracasei and Lb. rhamnosus in winter cheese and $L b$. paracasei ssp. paracasei and Lb. plantarum in summer cheese. Lactobacillus rhamnosus was detected only after 1 mo of ripening in winter cheese, whereas $L b$. paracasei ssp. paracasei was present at $7.7 \mathrm{log} \mathrm{cfu} / \mathrm{g}$ after $3 \mathrm{mo}$. Regarding summer production, $L b$. paracasei ssp. paracasei presence was not revealed at the end of the observation (SC5), whereas $L b$. plantarum was counted at $7.1 \mathrm{log} \mathrm{cfu} / \mathrm{g}$.

\section{LAB Clustering}

From the total amount of colonies randomly picked from all countable plates, 352 isolates from summer [number of isolates $=139$ ] and winter (number of isolates $=213$ ) cheese were further analyzed by RAPDPCR: 107 different strains were recognized. The RAPDPCR patterns (Figure 2) showed a high biodiversity of strains belonging to $E$. faecalis, $L b$. paracasei ssp. paracasei, Lb. plantarum, P. pentosaceus, and S. thermophilus. On the contrary, Lc. lactis ssp. cremoris (only detected in winter cheese) was characterized by a limited strain polymorphism. No high similarity was detected between summer and winter isolates; this could be attributable to the difference between the 2 productions: milk is obtained from cows fed with hay and stabled in winter and by cows fed in alpine pastures in summer. The RAPD-PCR typing also showed that among NSLAB isolated at different times during ripening, some strains (reported in Table 2) were frequently found.

\section{Physiological Characteristics of NSLAB}

The 107 strains representative for the NSLAB species found during ripening of winter and summer Puzzone di Moena cheeses ( $L b$. paracasei ssp. paracasei, $L b$. plantarum, and P. pentosaceus) were first characterized for their acidifying capacity (data not shown). Fifteen strains with limited ability to acidify UHT milk $(\mathrm{pH}$ $>5.5$ after $48 \mathrm{~h}$ ) were found, and they were also characterized for their proteolytic activity (Table 2). Three dominant strains (Lb. paracasei ssp. paracasei P397, $L b$. plantarum $\mathrm{P} 399$, and $P$. pentosaceus $\mathrm{P} 41$ ) showing the greatest $o$-phthalaldehyde values were then selected to be used as SAC.

\section{Fate of Secondary Adjunct Cultures}

The raw bulk milk used for experimental cheese production hosted 5.0 (d 1) to 4.9 (d 2) log cfu/mL of mesophilic cocci, 3.0 (d 1) to 3.1 (d 2) log cfu/mL of thermophilic cocci, 3.5 (d 1 and 2) $\log \mathrm{cfu} / \mathrm{mL}$ of mesophilic rods, 2.6 (d 1) to 2.7 (d 2) log cfu/mL of thermophilic rods, and 3.2 (d 1) to 3.0 (d 2) $\log \mathrm{cfu} / \mathrm{mL}$ of enterococci. At the same time of addition of the natural milk culture (primary starter), SAC was added at 2 different inoculation concentrations $\left(10^{3}\right.$ and $\left.10^{4} \mathrm{cfu} / \mathrm{mL}\right)$. A cheese sample from each inoculation level and a CC produced without SAC addition were then subjected to microbiological analyses at the third month of ripening. After strain isolation, the presence of the adjunct culture was verified by both microscopic inspection and RAPD-PCR analysis. The effectively dominant strains were recognized as $L b$. paracasei ssp. paracasei $\mathrm{P} 397$ and Lb. plantarum P399 (Figure 3), whose plate counts (the 2 species were counted together) ranged between 9.0 and $9.1 \mathrm{log}$ $\mathrm{cfu} / \mathrm{g}$ in ECB and 8.4 to $8.6 \mathrm{log} \mathrm{cfu} / \mathrm{g}$ in ECA. Pediococcus pentosaceus $\mathrm{P} 41$ was attested at a subdominant level as counted, in both ECA and ECB, from the $10^{-7}$ dilution (results not shown).

The other RAPD profiles detected in the experimental cheeses were mostly different from those found in traditional cheeses, but some strains could be recognized in both productions. Thus, the use of SAC reduced the biodiversity of LAB community found in 3-mo ripened cheeses, but a high level of SAC showed a too strong effect on strain composition, because almost only $L b$. plantarum P399 was found in ECB. Furthermore, SAC strains were not found in $\mathrm{CC}$, although it hosted the same species (results not shown). 
A.

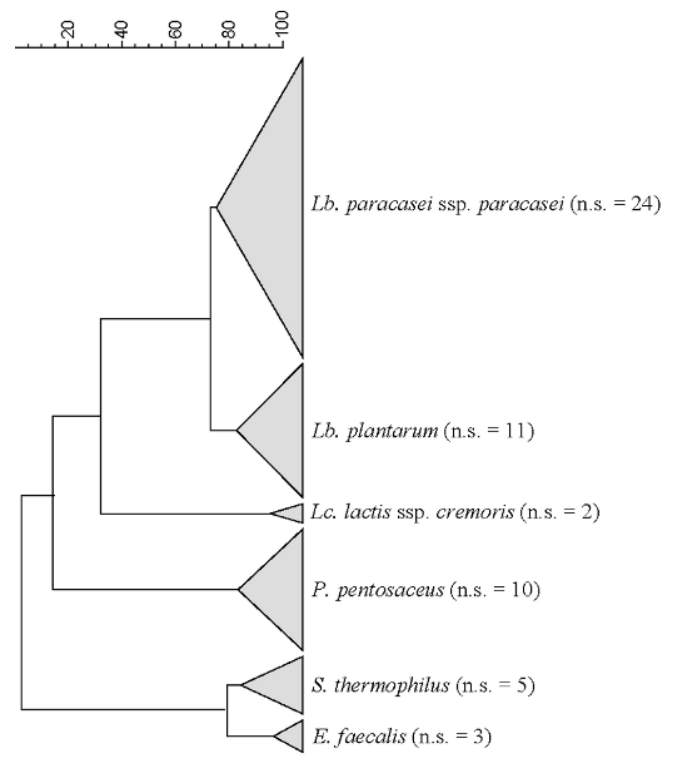

B.

.

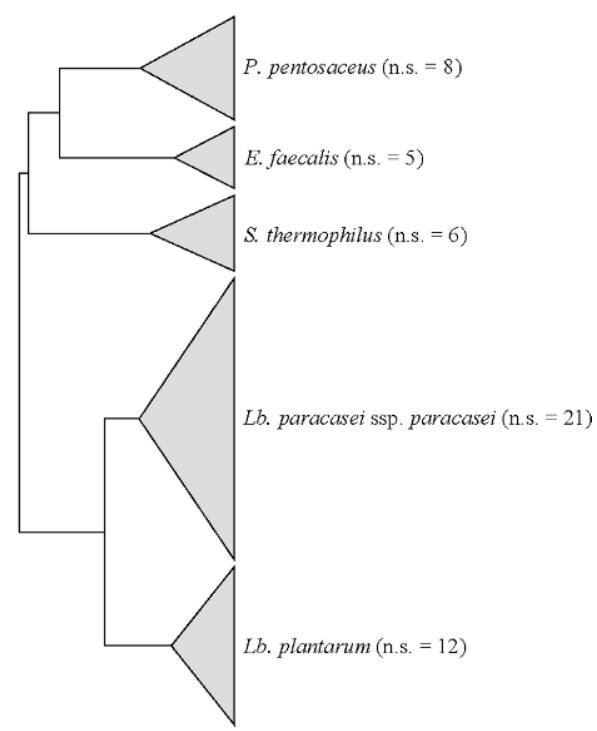

Figure 2. Dendrograms obtained from combined random amplification of polymorphic DNA-PCR patterns of lactic acid bacteria strains from traditional Puzzone di Moena cheeses: (A) winter production; (B) summer production. Upper lines indicate the percentage of similarity. n.s. = number of strains.

\section{Sensory Analyses}

Panelists agreed that all 3 cheeses were distinct in flavor and that the ECA was more similar in sensory quality to traditional Puzzone di Moena cheese (Table 3). Experimental cheese B was characterized by a strong loss of typicality.

\section{Volatile Organic Compound Composition}

Results from chromatographic analysis are reported in Table 4. In the headspace of the cheeses, 18 compounds were identified: 4 esters, 3 alcohols, 4 aldehydes, 6 fatty acids, and 1 ketone. The production of esters (ethyl butyrate, ethyl caproate, ethyl caprylate, and

Table 2. Acidification kinetics and proteolytic activity of dominant lactic acid bacteria (LAB) from traditional Puzzone di Moena cheeses

\begin{tabular}{|c|c|c|c|c|c|c|}
\hline \multirow[b]{2}{*}{ Species } & \multirow[b]{2}{*}{ Strain } & \multirow{2}{*}{$\begin{array}{c}\text { Sample } \\
\text { of first } \\
\text { isolation }\end{array}$} & \multicolumn{3}{|c|}{ Acidification kinetics $^{1}$} & \multirow[b]{2}{*}{ Proteolysis } \\
\hline & & & pH T0 & $\mathrm{pH} 24 \mathrm{~h}$ & $\mathrm{pH} 48 \mathrm{~h}$ & \\
\hline Lactobacillus paracasei ssp. paracasei & P95 & WC2 & 6.67 & 6.25 & 6.07 & 0.343 \\
\hline Lb. paracasei ssp. paracasei & $\mathrm{P} 117$ & WC2 & 6.67 & 6.12 & 5.90 & 0.112 \\
\hline Lb. paracasei ssp. paracasei & P397 & $\mathrm{SC} 2$ & 6.67 & 6.18 & 5.74 & 0.533 \\
\hline Lb. paracasei ssp. paracasei & $\mathrm{P} 411$ & $\mathrm{SC} 2$ & 6.67 & 6.01 & 5.51 & 0.257 \\
\hline Lb. paracasei ssp. paracasei & $\mathrm{P} 412$ & $\mathrm{SC} 2$ & 6.67 & 5.95 & 5.54 & 0.246 \\
\hline Lb. paracasei ssp. paracasei & $\mathrm{P} 414$ & $\mathrm{SC} 3$ & 6.67 & 6.02 & 5.57 & 0.347 \\
\hline Lactobacillus plantarum & P167 & WC4 & 6.67 & 5.98 & 5.58 & 0.220 \\
\hline Lb. plantarum & P205 & SC3 & 6.67 & 5.74 & 5.62 & 0.319 \\
\hline Lb. plantarum & P330 & SC3 & 6.67 & 6.45 & 6.36 & 0.210 \\
\hline Lb. plantarum & P399 & $\mathrm{SC} 2$ & 6.67 & 5.97 & 5.68 & 0.601 \\
\hline Pediococcus pentosaceus & $\mathrm{P} 41$ & WC3 & 6.67 & 6.23 & 5.94 & 0.524 \\
\hline$P$. pentosaceus & P147 & WC4 & 6.67 & 6.25 & 5.52 & 0.240 \\
\hline P. pentosaceus & P193 & WC5 & 6.67 & 5.95 & 5.50 & 0.301 \\
\hline P. pentosaceus & P206 & SC3 & 6.67 & 6.26 & 6.05 & 0.247 \\
\hline P. pentosaceus & $\mathrm{P} 224$ & SC3 & 6.67 & 6.20 & 5.84 & 0.223 \\
\hline
\end{tabular}

${ }^{1}$ Carried out in UHT milk.

${ }^{2} \mathrm{WC} 1$ = winter cheese at $24 \mathrm{~h}$; WC2 $=$ winter cheese at $10 \mathrm{~d}$; WC3 = winter cheese at 1 mo; WC4 = winter cheese at 2 mo; WC5 = winter cheese at 3 mo; SC2 = summer cheese at $10 \mathrm{~d}$; SC3 = summer cheese at 1 mo.

${ }^{3}$ Evaluated by $o$-phthalaldehyde assay. 


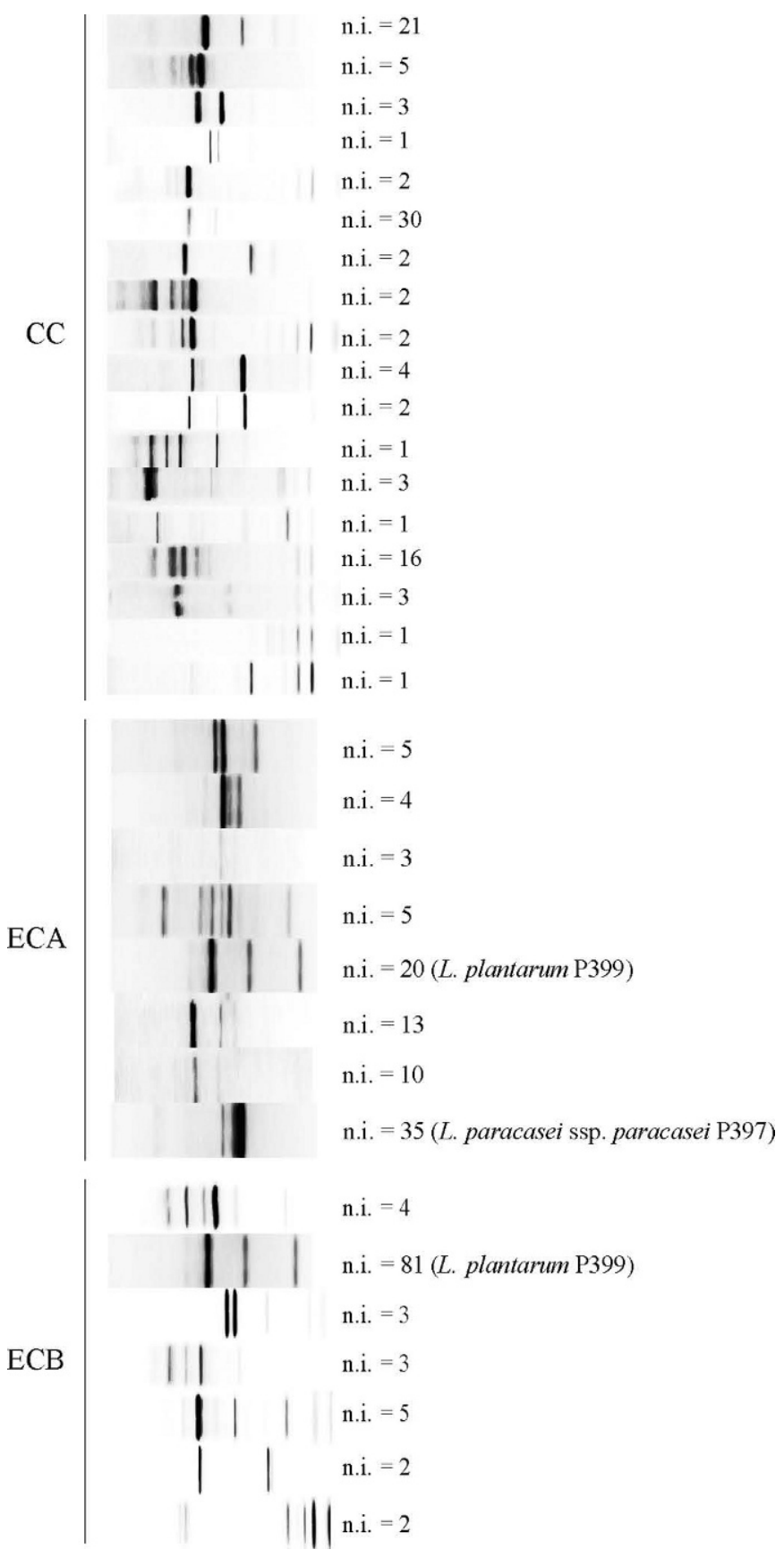

Figure 3. Random amplification of polymorphic DNA-PCR profiles of lactic acid bacteria isolates from Puzzone di Moena cheese manufactured without secondary adjunct cultures (control cheese, CC) and with secondary adjunct cultures at concentrations of $10^{3}$ (experimental cheese A, ECA) and $10^{4} \mathrm{cfu} / \mathrm{mL}$ (experimental cheese B, ECB). n.i. $=$ number of isolates.

ethyl caprate) was inversely linked to the use of secondary culture, because the total amount decreased from $9.58 \mathrm{mg} / \mathrm{kg}$ in CC to 1.64 and $2.30 \mathrm{mg} / \mathrm{kg}$ in ECA and ECB, respectively. Ethyl caproate was 8- and 9-fold lower for ECA and ECB, respectively, than for CC. Alco- hols were reduced by SAC similarly to the esters, even though the decrement was less pronounced; the total amount of alcohols was $3.61 \mathrm{mg} / \mathrm{kg}$ for CC, $1.68 \mathrm{mg} / \mathrm{kg}$ for ECA, and $2.61 \mathrm{mg} / \mathrm{kg}$ for ECB. Total aldehydes were approximately in the same range for $\mathrm{CC}(7.06 \mathrm{mg} / \mathrm{kg})$ and ECA $(6.78 \mathrm{mg} / \mathrm{kg})$, and the differences registered among the single aldehydes were negligible, whereas a massive reduction $(1.59 \mathrm{mg} / \mathrm{kg}$ of total aldehydes) was observed in case of ECB. Hexanal was the main aldehyde in all cheeses, and its greatest amount was in ECA $(5.18 \mathrm{mg} / \mathrm{kg})$. Acids were, among volatile organic compounds (VOC), the chemicals detected at the greatest levels, $41.84,31.17$, and $48.42 \mathrm{mg} / \mathrm{kg}$ for CC, ECA, and ECB, respectively. Experimental cheese A showed a similar presence of acetic acid $(8.84 \mathrm{mg} / \mathrm{kg})$ to $\mathrm{CC}$ $(7.74 \mathrm{mg} / \mathrm{kg})$; acetic acid production in ECB was barely $2.98 \mathrm{mg} / \mathrm{kg}$. Both ECA and ECB reduced the quantity of caproic (5.21 and $6.69 \mathrm{mg} / \mathrm{kg}$, respectively) and caprylic acid (2.44 and $3.45 \mathrm{mg} / \mathrm{kg}$, respectively) with respect to the CC (10.57 and $4.03 \mathrm{mg} / \mathrm{kg}$, respectively), and this reduction was of ca. 2-fold for ECA. Worthy of note are the differences regarding butyric and isovaleric acid: butyric acid detected in $\mathrm{CC}(8.48 \mathrm{mg} / \mathrm{kg})$ was twice that in ECA $(4.72 \mathrm{mg} / \mathrm{kg})$, and its amount in ECB $(18.59 \mathrm{mg} /$ $\mathrm{kg}$ ) was twice that in CC; ECB also showed the greatest amount of isovaleric acid with $12.37 \mathrm{mg} / \mathrm{kg}$, whereas $\mathrm{CC}$ and ECA contained 5.48 and $6.84 \mathrm{mg} / \mathrm{kg}$ of this compound, respectively. Among ketones, acetoin, which does not impart flavor (Beresford and Williams, 2004), was in the range of 0.15 to $0.30 \mathrm{mg} / \mathrm{kg}$ with the lowest amount for ECA and the highest for ECB.

\section{DISCUSSION}

To develop characteristic flavors during ripening, adjunct cultures have been used in cheese making for years (El Soda et al., 2000). Nonstarter LAB represent a natural component of all bacterial-ripened cheeses; they may enter cheese through processing equipment or through milk and grow to high numbers during ripening (Beresford et al., 2001). One of the most promising strategies to control NSLAB populations is to employ well-characterized LAB, in particular Lactobacillus spp., as adjunct cultures that suppress the emergence of wild NSLAB (Broome et al., 1990; Crow et al., 2001).

In the present study, changes in LAB and NSLAB communities during the ripening of seasonal Puzzone di Moena cheese were followed over a period of $3 \mathrm{mo}$. The initial LAB composition of curd was remarkably different from that of ripened cheese. At $24 \mathrm{~h}, S$. thermophilus, the typical starter culture of the natural milk culture used in cheese-making plants producing Puzzone di Moena cheese, dominated the lactic population in both winter and summer production, whereas, after 
Table 3. Critical sensory attributes evaluated in experimental Puzzone di Moena cheeses ${ }^{1}$

\begin{tabular}{|c|c|c|c|c|c|c|c|c|c|c|c|c|}
\hline \multirow[b]{3}{*}{ Assessors } & \multicolumn{12}{|c|}{ Sensory descriptors } \\
\hline & \multicolumn{3}{|c|}{ Egg } & \multicolumn{3}{|c|}{ Ammonium } & \multicolumn{3}{|c|}{ Stall } & \multicolumn{3}{|c|}{ Butyric } \\
\hline & $\mathrm{CC}$ & ECA & ECB & $\mathrm{CC}$ & ECA & ECB & $\mathrm{CC}$ & ECA & ECB & $\mathrm{CC}$ & ECA & $\mathrm{ECB}$ \\
\hline 1 & + & + & \pm & + & + & - & + & + & ++ & + & + & ++ \\
\hline 2 & + & + & - & \pm & + & \pm & \pm & \pm & + & + & + & ++ \\
\hline 3 & + & + & - & + & + & - & + & + & ++ & + & + & ++ \\
\hline 4 & + & + & - & + & + & - & + & + & + & + & + & ++ \\
\hline 5 & + & + & - & + & + & \pm & + & + & ++ & + & + & ++ \\
\hline 6 & + & \pm & - & \pm & \pm & - & + & \pm & ++ & + & + & ++ \\
\hline
\end{tabular}

3 mo of ripening, $L b$. paracasei ssp. paracasei and $L b$. plantarum were detected as dominant species in winter and summer cheese, respectively. Both species are generally reported as NSLAB of several ripened cheeses (De Angelis et al., 2001; Randazzo et al., 2002; Antonsson et al., 2003; Di Cagno et al., 2007). Pediococcus pentosaceus was also found at lower concentrations, although always at almost dominant levels, during the whole ripening time considered in our study. This species is allotted into the NSLAB group (Stanton et al., 1998), but it is not generally one of the main NSLAB species. However, $P$. pentosaceus is potentially of high interest during ripening [e.g., it has been used as an adjunct starter to accelerate flavor development in reduced-fat Cheddar cheese (Bhowmik et al., 1990) and in combination with other starter cultures to produce

Table 4. Analysis of volatile organic compounds emitted from experimental Puzzone di Moena cheeses ${ }^{1}$

\begin{tabular}{lccr}
\hline Chemicals $^{2}$ & CC & ECA & ECB \\
\hline Ethyl butyrate & 1.48 & 0.47 & 0.96 \\
Hexanal & 4.62 & 5.18 & 1.01 \\
Heptanal & 1.19 & 0.86 & 0.28 \\
Isoamylic alcohol & 1.10 & 0.29 & 1.05 \\
Ethyl caproate & 4.46 & 0.58 & 0.48 \\
Octanal & 0.64 & 0.32 & 0.11 \\
Acetoin & 0.27 & 0.15 & 0.30 \\
Hexanol & 1.41 & 0.93 & 0.29 \\
Nonanal & 0.61 & 0.42 & 0.19 \\
Ethyl caprylate & 2.78 & 0.48 & 0.56 \\
Acetic acid & 7.74 & 8.84 & 2.98 \\
Propionic acid & 3.37 & 2.89 & 4.34 \\
Butyric acid & 8.48 & 4.72 & 18.59 \\
Ethyl caprate & 0.86 & 0.11 & 0.30 \\
Isovaleric acid & 5.48 & 6.84 & 12.37 \\
Caproic acid & 10.57 & 5.21 & 6.69 \\
2-Phenylethanol & 0.28 & 0.05 & 0.48 \\
Caprylic acid & 4.03 & 2.44 & 3.45 \\
\hline
\end{tabular}

${ }^{1}$ Manufactured without secondary adjunct cultures (CC) and with secondary adjunct cultures at concentrations of $10^{3}$ (ECA) and $10^{4}$ $\mathrm{cfu} / \mathrm{mL}(\mathrm{ECB}) . \mathrm{CC}=$ control cheese; $\mathrm{ECA}=$ experimental cheese $\mathrm{A}$; $\mathrm{ECB}=$ experimental cheese $\mathrm{B}$.

${ }^{2}$ Expressed (in $\mathrm{mg} / \mathrm{kg}$ ) as 4-methyl-2-pentanone (internal standard). Chemicals are shown following their retention time.
Gouda cheese (Verachia, 2005)]. Our results are in agreement with the common observation that the number of NSLAB increase rapidly, reaching maximum levels of $10^{8} \mathrm{cfu} / \mathrm{g}$ in cheese within a few days (Stanton et al., 1998).

With the aim of constituting a SAC to be linked to the typicality of the final product, the isolated NSLAB were characterized for their acidifying and proteolytic activity. Because the acidification of curd does not depend on SAC, our attention was addressed to the NSLAB with low acidifying capacity, which do not influence the activity of primary starters. Among such strains, those with the greatest proteolytic aptitude, which is one of the main, if not the most important, characteristics of NSLAB, were preferred. The last criterion of selection was the persistence in the dominant populations throughout cheese ripening: $L b$. paracasei ssp. paracasei P397, Lb. plantarum P399, and P. pentosaceus $\mathrm{P} 41$ were finally chosen to be used as a triple SAC in experimental cheese making at an industrial level. Our SAC is a mix of obligately and facultatively homofermentative species, and it was added at 2 different inoculation levels $\left(10^{3}\right.$ and $\left.10^{4} \mathrm{cfu} / \mathrm{mL}\right)$, to verify their contribution to the overall characteristics of final cheese. Other authors reported on the use of mixed NSLAB cultures (e.g., Puchades et al. (1989) compared the effect of adding different lactobacilli such as $L b$. casei, Lb. paracasei, Lb. plantarum, and Lactobacillus brevis during Cheddar cheese making). Lee et al. (1990) demonstrated that although the use of some homofermentative mesophilic lactobacilli led to more intense desirable cheese flavor, others caused high acidity, bitterness, off flavors, and open and crumbly textures, which clearly indicate the importance of culture selection. Our study showed that the 3 strains isolated from Puzzone di Moena cheese with characteristics of desirable NSLAB are able to colonize the NSLAB community throughout ripening (Figure 3).

Sensory analyses and VOC contributed to choose the optimal level of SAC inoculation. All 6 panelists agreed 
in finding CC, ECA, and ECB different from one another, and the overall preference was toward ECA. Regarding VOC analyses, from relative abundance percentages of the different chemical classes detected in the cheese samples (Table 4), we observed that acids were the most significant contributors to the volatile profile of all 3 cheeses; aldehydes and esters also consistently contributed to the VOC profile of CC, whereas only aldehydes contributed to the VOC profile of ECA. Fatty acids are important, or even predominant, components of the flavor of many cheese types. In general, long-chain fatty acids play a minor role in the flavor, given their relatively high perception thresholds; $\mathrm{C}_{4}$ $\mathrm{C}_{12}$ fatty acids have much lower perception thresholds, and each has a characteristic note. Among acids, acetic acid, characterized by a vinegar note, was the main acid of ECA; it is a major odorant of several cow's milk cheeses, such as Cheddar, Gruyère, Roncal, and Emmental (Curioni and Bosset, 2002). Our experimental cheeses did not consistently differ for the amount of caproic and caprylic acid, which was lower than that produced in CC. These acids are known as important odorants of aged cheeses. The greatest differences between ECA and ECB in VOC were due to butyric and isovaleric acid. Butyric acid has a rancid cheese-like odor, and large amounts of this volatile acid are undesirable. Isovaleric acid is a branched-chain fatty acid characterized by a rancid, cheesy, sweaty, and putrid odor (Yvon and Rijnen, 2001). From these results, $10^{3} \mathrm{cfu} /$ $\mathrm{mL}$ was finally suggested as the inoculation level of SAC to reduce variability of Puzzone di Moena cheese production; it reduces NSLAB strain composition without losing cheese typicality as demonstrated by sensory and VOC analysis.

\section{CONCLUSIONS}

Four main conclusions can be draft from the present study: 1) LAB are present at high numbers during ripening of Puzzone di Moena cheese; 2) there are no big differences in LAB species composition between summer and winter production, but strains found are significantly different; 3) SAC are able to dominate over indigenous LAB, thus avoiding strain fluctuation during cheese ripening; and 4) SAC inoculum should not be greater than $10^{3} \mathrm{cfu} / \mathrm{mL}$ to avoid cheese taste flattening.

\section{ACKNOWLEDGMENTS}

This study was financially supported by the project "Valorizzazione e salvaguardia della microflora caratteristica delle produzioni casearie italiane" of the Italian Ministry of Agriculture and Forestry. We wish to thank the staff of Caseificio Sociale di Predazzo e Moena
(Predazzo, Trento, Italy) for its cooperation and supervision of the experimental cheese production. The authors are also grateful to Marina Agostini and Giovanna Facchinelli for their technical support.

\section{REFERENCES}

Antonsson, M., G. Molin, and Y. Ardö. 2003. Lactobacillus strains isolated from Danbo cheese as adjunct cultures in a cheese model system. Int. J. Food Microbiol. 85:159-169.

Beresford, T. P., N. A. Fitzsimons, N. L. Brennan, and T. M. Cogan. 2001. Recent advances in cheese microbiology. Int. Dairy J. $11: 259-274$.

Beresford, T., and A. Williams. 2004. The microbiology of cheese ripening. Pages 287-318 in Cheese: Chemistry, Physics and Microbiology. Vol. 1. P. F. Fox, P. L. H. McSweeney, T. M. Cogan, and T. P. Guinee, ed. Chapman and Hall, London, UK.

Bhowmik, T., R. Riesterer, M. A. J. S. van Boekel, and E. H. Marth. 1990. Characteristics of low-fat cheese made with added Micrococcus or Pediococcus species. Milchwissenschaft 45:230-235.

Broome, M. C., D. A. Krause, and M. W. Hickey. 1990. The isolation and characterization of lactobacilli from Cheddar cheese. Aust. J. Dairy Technol. 45:60-66.

Carlin, S., and G. Versini. 2005. La caratterizzazione dei formaggi trentini attraverso la frazione volatile. Caratterizzazione di formaggi tipici dell'arco alpino: Il contributo della ricerca. F. Gasperi and G. Versini, ed. Temi, San Michele all'Adige, Italy.

Church, F. C., D. H. Porter, G. L. Catignani, and H. E. Swaisgood. 1985. An o-phthalaldehyde spectrophotometric assay for proteinases. Anal. Biochem. 146:343-348.

Corroler, D., I. Mangin, N. Desmasures, and M. Gueguen. 1998. An ecological study of lactococci isolated from raw milk in the Camembert cheese registered designation of origin area. Appl. Environ. Microbiol. 64:4729-4735.

Crow, V., B. Curry, and M. Hayes. 2001. The ecology of non-starter lactic acid bacteria (NSLAB) and their use as adjuncts in New Zealand Cheddar. Int. Dairy J. 11:275-283.

Curioni, P. M. G., and J. O. Bosset. 2002. Key odorants in various cheese types as determined by gas chromatography-olfactometry. Int. Dairy J. 12:959-984.

De Angelis, M., A. Corsetti, N. Tosti, J. Rossi, M. R. Corbo, and M. Gobbetti. 2001. Characterization of non-starter lactic acid bacteria from Italian ewe cheeses based on phenotypic, genotypic, and cell wall protein analyses. Appl. Environ. Microbiol. 67:20112020.

Di Cagno, R., S. Buchin, S. de Candia, M. De Angelis, P. F. Fox, and M. Gobbetti. 2007. Characterization of Italian cheeses ripened under nonconventional conditions. J. Dairy Sci. 90:2689-2704.

El Soda, M., S. A. Madkor, and P. S. Tong. 2000. Adjunct cultures: Recent developments and potential significance to the cheese industry. J. Dairy Sci. 83:609-619.

Endrizzi, I., F. Gasperi, F. Biasoli, V. Framondino, E. Aprea, D. Mott, and S. Calovi. 2005. La qualità sensoriale di tre formaggi trentini a crosta lavata. Caratterizzazione di formaggi tipici dell'arco alpino: Il contributo della ricerca. F. Gasperi and G. Versini, ed. Temi, San Michele all'Adige, Italy.

Ercolini, D., G. Moschetti, G. Blaiotta, and S. Coppola. 2001. Behavior of variable V3 region from 16S rDNA of lactic acid bacteria in denaturing gradient gel electrophoresis. Curr. Microbiol. 42:199-202

Fitzsimons, N. A., T. M. Cogan, S. Condon, and T. Bereford. 1999. Phenotypic and genotypic characterization of nonstarter lactic acid bacteria in mature cheddar cheese. Appl. Environ. Microbiol. 65:3418-3426.

Franciosi, E., L. Settanni, A. Cavazza, and E. Poznanski. 2008. Presence of enterococci in raw cow's milk and "Puzzone di Moena" cheese. J. Food Process. Preserv. (accepted).

Fryer, T. F., and M. E. Sharpe. 1966. Pediococci in Cheddar cheese. J. Dairy Res. 33:325-331. 
Gobbetti, M., B. Folkertsma, P. F. Fox, A. Corsetti, E. Smacchi, M. De Angelis, J. Rossi, K. Kilcawley, and M. Cortini. 1999. Microbiology and biochemistry of Fossa (pit) cheese. Int. Dairy J. 9:763-773.

Gregersen, T. 1978. Rapid method for distinction of gram-negative from gram-positive bacteria. Appl. Microbiol. Biotechnol. 5:123-127.

Heilig, H. G., E. G. Zoetendal, E. E. Vaughan, P. Marteau, A. D. Akkermans, and W. M. de Vos. 2002. Molecular diversity of Lactobacillus spp. and other lactic acid bacteria in the human intestine as determined by specific amplification of $16 \mathrm{~S}$ ribosomal DNA. Appl. Environ. Microbiol. 68:114-123.

Jackson, C. R., P. J. Fedorka-Cray, and J. B. Barrett. 2004. Use of genus- and species-specific multiplex PCR for identification of enterococci. J. Clin. Microbiol. 42:3558-3565.

Jordan, K. N., and T. M. Cogan. 1993. Identification and growth of non-starter lactic acid bacteria in Irish Cheddar cheese. Ir. J. Agric. Food Res. 32:47-55.

Lee, B. H., L. C. Laleye, R. E. Simard, R. A. Holly, D. B. Emmys, and R. N. Giro. 1990. Influence of homofermentative lactobacilli on physicochemical and sensory properties of Cheddar cheese. J. Food Sci. 55:386-390.

Maidak, B. L., J. R. Cole, T. G. Lilburn, C. T. Parker Jr., P. R. Saxman, R. J. Farris, G. M. Garrity, G. J. Olsen, T. M. Schmidt, and J. M. Tiedje. 2001. The RDP-II (Ribosomal Database Project). Nucleic Acids Res. 29:173-174.

Micari, P., V. Sarullo, R. Sidari, and A. Caridi. 2007. Physico-chemical and hygienic characteristics of the Calabrian raw milk cheese, Caprino d'Aspromonte. Turk. J. Vet. Anim. Sci. 31:55-60.

Mora, D., M. G. Fortina, C. Parini, and P. L. Manachini. 1997. Identification of Pediococcus acidilactici and Pediococcus pentosaceus based on $16 \mathrm{~S}$ rRNA and $l d h D$ gene-targeted multiplex PCR analysis. FEMS Microbiol. Lett. 151:231-236.

Morea, M., F. Baruzzi, F. Cappa, and P. S. Cocconcelli. 1998. Molecular characterization of the Lactobacillus community in traditional processing of Mozzarella cheese. Int. J. Food Microbiol. 43:53-60.

Parente, E., and T. M. Cogan. 2004. Starter cultures: General aspects. Pages 123-148 in Cheese: Chemistry, Physics and Microbiology. Vol. 1. P. F. Fox, P. L. H. McSweeney, T. M. Cogan, and T. P. Guinee, ed. Chapman and Hall, London, UK.

Peterson, S. D., and R. T. Marshall. 1990. Non-starter lactobacilli in Cheddar cheese: A review. J. Dairy Sci. 73:1393-1410.
Poznanski, E., A. Cavazza, F. Cappa, and P. S. Cocconcelli. 2004. Alpine environment microbiota influences the bacterial development in traditional raw milk cheese. Int. J. Food Microbiol. 92:141-151.

Puchades, R., L. Lemieux, and R. E. Simard. 1989. Evolution of free amino acids during the ripening of Cheddar cheese containing added Lactobacillus strains. J. Food Sci. 54:885-888.

Randazzo, C. L., S. Torriani, A. D. L. Akkermans, W. M. de Vos, and E. E. Vaughan. 2002. Diversity, dynamics, and activity of bacterial communities during production of an artisanal Sicilian cheese as evaluated by $16 \mathrm{~S}$ rRNA analysis. Appl. Environ. Microbiol. 68:1882-1892.

Stackebrandt, E., and B. M. Goebel. 1994. Taxonomic note: A place for DNA-DNA reassociation and 16S rRNA sequence analysis in the present species definition in bacteriology. Int. J. Syst. Bacteriol. 44:846-849.

Stanton, C., G. Gardiner, P. B. Lynch, J. K. Collins, G. Fitzgerald, and R. P. Ross. 1998. Probiotic cheese. Int. Dairy J. 8:491-496.

Torriani, S., G. E. Felis, and F. Dellaglio. 2001. Differentiation of Lactobacillus plantarum, $L$. pentosus, and $L$. paraplantarum by recA gene sequence analysis and multiplex PCR assay with recA gene-derived primers. Appl. Environ. Microbiol. 67:3450-3454.

Turner, K. W., R. C. Lawrence, and J. Levriere. 1986. A microbiological specification for milk for aseptic cheese making. N. Z. J. Dairy Sci. Technol. 21:249-254.

van den Braak, N., E. Power, R. Anthony, H. Endtz, H. A. Verbrugh, and A. Van Belkum. 2000. Random amplification of polymorphic DNA versus pulsed field gel electrophoresis of SmaI DNA macrorestriction fragments for typing strains of vancomycin-resistant enterococci. FEMS Microbiol. Lett. 192:45-52.

Verachia, W. 2005. Application of Pediococcus spp. as adjunct cultures in Gouda cheese. MS Thesis. University of Pretoria, Pretoria, South Africa.

Ward, L. J. H., and M. J. Timmins. 1999. Differentiation of Lactobacillus casei, Lactobacillus paracasei and Lactobacillus rhamnosus by polymerase chain reaction. Lett. Appl. Microbiol. 29:90-92.

Williams, A. G., S.-C. Choi, and J. M. Banks. 2002. Variability of the species and strain phenotype composition of the non-starter lactic acid bacterial population of Cheddar cheese manufactured in a commercial creamery. Food Rev. Int. 35:483-493.

Yvon, M., and L. Rijnen. 2001. Cheese flavour formation by amino acid catabolism. Int. Dairy J. 11:185-201. 